\title{
Integrated strategy for in vitro characterization of a bileaflet mechanical aortic valve
}

\author{
Francesca Maria Susin², Stefania Espa ${ }^{1^{*}} \mathbb{B}$, Riccardo Toninato ${ }^{2}$, Stefania Fortini ${ }^{1}$ and Giorgio Querzoli ${ }^{3}$
}

\author{
*Correspondence: \\ stefania.espa@uniroma1.it \\ ${ }^{1}$ Department of Civil \\ and Environmental \\ Engineering, Sapienza \\ University of Rome, Rome, \\ Italy \\ Full list of author information \\ is available at the end of the \\ article
}

\begin{abstract}
Background: Haemodynamic performance of heart valve prosthesis can be defined as its ability to fully open and completely close during the cardiac cycle, neither overloading heart work nor damaging blood particles when passing through the valve. In this perspective, global and local flow parameters, valve dynamics and blood damage safety of the prosthesis, as well as their mutual interactions, have all to be accounted for when assessing the device functionality. Even though all these issues have been and continue to be widely investigated, they are not usually studied through an integrated approach yet, i.e. by analyzing them simultaneously and highlighting their connections.

Results: An in vitro test campaign of flow through a bileaflet mechanical heart valve (Sorin Slimline $25 \mathrm{~mm}$ ) was performed in a suitably arranged pulsatile mock loop able to reproduce human systemic pressure and flow curves. The valve was placed in an elastic, transparent, and anatomically accurate model of healthy aorta, and tested under several pulsatile flow conditions. Global and local hydrodynamics measurements and leaflet dynamics were analysed focusing on correlations between flow characteristics and valve motion. The haemolysis index due to the valve was estimated according to a literature power law model and related to hydrodynamic conditions, and a correlation between the spatial distribution of experimental shear stress and pannus/thrombotic deposits on mechanical valves was suggested. As main and general result, this study validates the potential of the integrated strategy for performance assessment of any prosthetic valve thanks to its capability of highlighting the complex interaction between the different physical mechanisms that govern transvalvular haemodynamics.

Conclusions: We have defined an in vitro procedure for a comprehensive analysis of aortic valve prosthesis performance; the rationale for this study was the belief that a proper and overall characterization of the device should be based on the simultaneous measurement of all different quantities of interest for haemodynamic performance and the analysis of their mutual interactions.
\end{abstract}

Keywords: Pulse duplicator, Image velocimetry, Valve leaflets dynamics, Haemolysis index

\section{Background}

Incidence of heart valve diseases is growing in western countries with population age and life expectancy increasing [1, 2]. Satisfactory transvalvular haemodynamic 
conditions and heart pump function are usually restored at the short- and mid-term after valve replacement. Nevertheless, current prostheses are still quite far from representing the 'optimum prosthetic valve'. Mechanical heart valves (MHVs) express high durability but induce flow patterns different from those observed in healthy subjects $[3,4]$. Also, MHVs studies highlighted a sharp tendency to thrombus formation, which requires life-long anticoagulant therapy [2], as well as to haemolysis [5]. On the other hand, biological prostheses haemodynamics is usually nearly physiological but they show short durability mainly due to leaflets stiffening caused by shear stresses and calcification phenomena [6-8]. In both cases the fluid-structure interaction plays a fundamental role in determining prosthesis functionality, hence a thorough analysis of flow characteristics close to the valve is essential to assess its overall performance [9]. The work by Dasi et al. [10], who described the interaction between vorticity and leaflet kinematics of a bileaflet mechanical heart valve (BMHV), is a first important step in that direction. However, literature usually focuses on either global functionality, to assess whether the artificial valve overloads heart work, or local functionality, to quantify the shear stress field and its potential effects in terms of blood cells damage and leaflets degeneration. Several in vitro and in vivo studies were aimed at the experimental estimation of global haemodynamic parameters as the transvalvular pressure drop, the effective orifice area (EOA) or the regurgitant and leakage volumes (see e.g. [11-16]). As for valve dynamics, attention has been most devoted to study the behavior in time of the valve area for both biological and mechanical prosthesis [17-20], while the leaflets motion of bileaflet mechanical heart valve (BMHV) has been somehow less investigated despite the importance of the issue [10, 21-23]. Several numerical studies focused on the occluders dynamics using fluid-structure interactions approach [22, 24-27]. Flow patterns and shear stress distribution in correspondence of the valve have been extensively investigated both numerically [6,24, 28, 29] and in vitro [20, 30-34]. Moreover, several literature works deal with red blood cells (RBCs) or platelets damage, providing haemolysis laws to characterize the dangerousness of the flow through the prosthetic device [35-39] or of the valve itself [40].

Even though these studies provide a solid and recognized base as single interpretation of a complex phenomenon, a unique strategy to characterize the valve overall hydrodynamic performance is still vacant. To this aim, this study proposes an integrated approach able to provide simultaneous in vitro measurements of (1) pressure and flow waves across a prosthetic valve; (2) leaflets position in time; (3) flow field and shear stress distribution (near and far fields) downstream of the valve (notice that all these quantities are required by international standards), and to highlight mutual interactions between all investigated mechanisms. The tests were performed in a mock loop simulating the human systemic circulation in a model of healthy ascending aorta.

\section{Methods}

The apparatus here adopted is the pulse duplicator (PD) that was already described in its basic functional elements and capability of reproducing physiological flows [41-47]. The PD has been adapted with an ad-hoc simplified replica of the human ascending aorta (AA) connected to the left ventricle outflow tract (LVOT) (Fig. 1a). AA was made of transparent compliant silicone rubber (Sylgard-184, Tensile Modulus $1050 \mathrm{psi}$ and $2 \mathrm{~mm}$ 


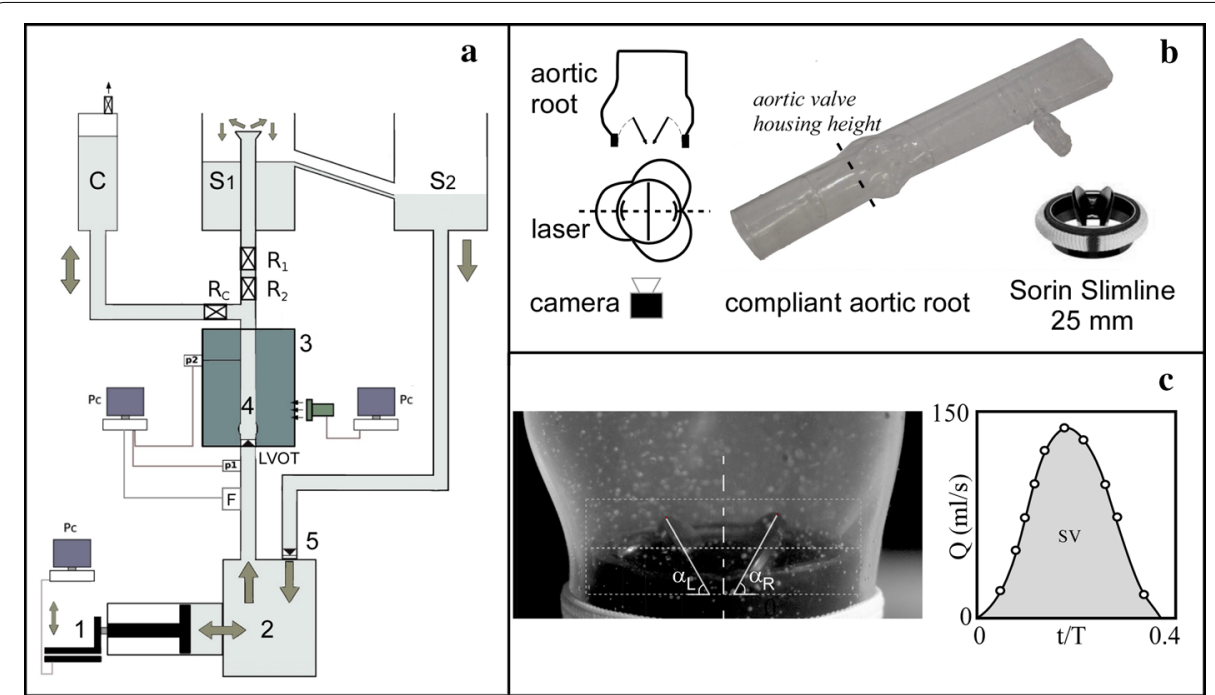

Fig. 1 a Sketch of the experimental apparatus: 1 Piston pump; 2 ventricular chamber; 3 aortic chamber; 4 aorta; 5 mitral valve; $R 1$ and $R 2$ peripheral resistance; $R C$ compliance flow regulator; $C$ compliance chamber; S1 right atrial chamber, S2 left atrial chamber. b Set up of camera, laser sheet, valve and aortic root mutual position; aortic root model plus the adopted mechanical valve. c Measuring tool for leaflet tilting angles [right $\left(a_{R}\right)$ and left $\left.\left(a_{L}\right)\right]$, and chosen time instants for leaflets dynamic measurements, in the ejection phase. The grey area represents the SV pumped into the aorta

thickness) by dipping technique, choosing shape and dimensions in accordance to average adult population characteristics, sinuses of Valsalva included (aortic annulus inner diameter $\mathrm{D}=25 \mathrm{~mm}$, AA height $\mathrm{H}=70 \mathrm{~mm}$, aortic root radius/aortic radius $=1.4$, height of sinuses of Valsalva $=20 \mathrm{~mm}$ ). As discussed in detail in [46] and in [47], the distensibility of the aorta in the interval between the systolic peak and the diastole, has been reproduced by imposing a correct percentage diameter change (10-16\%) during the cardiac cycle accordingly to the physiological range [48, 49]. A bileaflet Sorin Bicarbon Slimline valve $\left[50,51\right.$ ] (nominal diameter $d_{v}=25 \mathrm{~mm}$, comprehensive of the suture annulus-Fig. 1b) commonly used for replacement was placed at surgical height inside the aortic root, using a proper housing. Valve-mock root mutual position provides a typical orientation [30], with a leaflet dedicated to one sinus and the other in correspondence to a commissure (Fig. 1b).

Two piezoelectric sensors (PCB Piezotronics ${ }^{\circledR} 1500$ series, Fig. 1a - $\mathrm{P}_{1}$ and $\mathrm{P}_{2^{-}}$) located respectively $3,5 \mathrm{D}$ upstream and $6,25 \mathrm{D}$ downstream the aortic valve, provided aortic $\left(\mathrm{p}_{\mathrm{a}}\right)$ and ventricular $\left(\mathrm{p}_{\mathrm{v}}\right)$ pressure. An electromagnetic flowmeter (501D Carolina Medical Electronics, Fig. 1a -F-) recorded the aortic flow rate during cardiac cycle. An example of recorded forward flow rate $Q$ in non-dimensional time $t / T$, where $T$ is the dimensional period of the cycle, is reported in Fig. 1c. Positive $Q$ gives the systolic outflow rate while the grey area equals the ejected stroke volume (SV). The time law of the ventricle volume change was assigned to mimic a physiological behavior (the flow curve used in the commercial, FDA approved, ViVitro ${ }^{\circledR}$ mock loop system). To fulfill the geometric similarity a geometric aspect-ratio 1:1 was set on the investigated area. Farther, since water (whose viscosity is about one-third of that of the blood) was used as working fluid, to respect the dynamic similarity, for a given physiological SV, the period of the cardiac cycle adopted in the experiments was set equal to three times the physiologic one. In the 
considered settings of the flow control parameters the peak velocity varied in the range $0.15-0.25 \mathrm{~m} / \mathrm{s}$ and non-dimensional parameters, Reynolds and Womersley numbers, resulted respectively $2500<\operatorname{Re}<4500$ and $14<$ Wo $<17$. The similarity with respect to the leaflet motion is also matched since scale effects are not expected [43].

\section{Pressure and EOA measurements}

The ability of the PD to accurately reproduce physiological ventricular and aortic pressures was assessed by comparing experimental and real pressure behaviors in both shape and reference values (min and max systolic pressures and mean aortic pressure $\overline{\mathrm{p}_{\mathrm{a}}}$ over the period T). Sensitivity of the PD to haemodynamic input conditions as SV and T was also verified. To this aim we examined the variability of both the mean (evaluated over the period of forward flow) transvalvular pressure drop $\Delta \mathrm{p}_{\mathrm{m}}=\overline{\left(\mathrm{p}_{\mathrm{v}}-\mathrm{p}_{\mathrm{a}}\right)}$ and the EOA corresponding to five different combinations of the parameters $\mathrm{SV}$ and $\mathrm{T}$, listed in Table 1.

An Additional file 1 containing the pressure fields across the valve is included [see pressure_data.xls].

Haemodynamic input conditions SV and T adopted in PD sensitivity analysis tests. Fundamental global haemodynamic parameters calculated as averages over 100 nonconsecutive cycles are also reported; $\Delta \mathrm{p}_{\mathrm{m}}$ : mean transvalvular pressure drop over the ejection period; $\mathrm{Q}_{\mathrm{rms}}$ : root mean square aortic flow rate over the ejection period; EOA. Recall that to ensure dynamic similarity between the in vitro model and the real environment, experimental flow rate was set to $1 / 3$ of the physiological one.

It has to be noted that $\Delta \mathrm{p}_{\mathrm{m}}$ and the EOA are the global parameters that have to be checked in vitro to assess the systolic haemodynamic performance of implanted heart valves according to the European Standard EN ISO 5840 [52]. In particular, the EOA has to be calculated as:

$$
\mathrm{EOA}=\frac{\mathrm{Q}_{\mathrm{rms}}}{51.6 \sqrt{\frac{\Delta \mathrm{p}_{\mathrm{m}}}{\rho}}}
$$

where $\mathrm{Q}_{\mathrm{rms}}$ is the flow root mean square in the ejection period measured in $\mathrm{ml} / \mathrm{s}$ and $\rho$ is the fluid density in $\mathrm{g} / \mathrm{cm}^{3}$, thus resulting in EOA given in $\mathrm{cm}^{2}$ when $\Delta \mathrm{p}_{\mathrm{m}}$ is in $\mathrm{mmHg}$.

\section{Haemolysis index}

To estimate blood cell damage due to mechanical stress, usually the haemolysis index $(\mathrm{HI})$, is considered. $\mathrm{HI}(\%)$ is defined as the ratio between the increase in plasma free

Table 1 Experimental parameters

\begin{tabular}{lllllll}
\hline Test & $\mathbf{S V}(\mathbf{m l})$ & $\mathbf{T}(\mathbf{s})$ & $\begin{array}{l}\text { Equivalent beat } \\
\text { rate }(\mathbf{b p m})\end{array}$ & $\mathbf{\Delta} \mathbf{p}_{\mathbf{m}}\left(\mathbf{m m}_{\mathbf{H g}}\right)$ & $\mathbf{Q}_{\mathbf{r m s}}(\mathbf{l} / \mathbf{m i n})$ & $\mathbf{E O A}\left(\mathbf{c m}^{\mathbf{2}}\right)$ \\
\hline 1 & 64 & 1.8 & 100 & 22.23 & 6.53 & 1.34 \\
2 & 54 & 2.4 & 75 & 13.23 & 4.39 & 1.17 \\
3 & 64 & 2.4 & 75 & 15.03 & 5.29 & 1.33 \\
4 & 80 & 2.4 & 75 & 19.26 & 6.68 & 1.48 \\
5 & 64 & 3.0 & 60 & 9.36 & 4.07 & 1.29 \\
\hline
\end{tabular}


haemoglobin $\left(\Delta \mathrm{H}_{\mathrm{b}}\right)$ and the whole haemoglobin contained in a sample of blood $\left(\mathrm{H}_{\mathrm{b}}\right)$ exposed to the action of flow shear stress [53]. Among the proposed formulations (for a comprehensive review see $[37,53,54]$ ), and with the only aim of having a preliminary quantification of potential haemolysis, we adopted the power law model proposed by Giersiepen [55] used for calculating the HI for one single passage through mechanical heart valves:

$$
\mathrm{HI}(\%)=\frac{\Delta H_{b}}{H_{b}} 100=3.62 \cdot 10^{-5} \cdot \mathrm{t}_{\exp }^{0.785} \cdot \tau^{2.416}
$$

where, $t_{\exp }$ is the duration of the exposure to the 'active' shear stress $\tau$.

\section{Leaflets dynamics}

Leaflets dynamics was investigated through a semi-automatic image analysis technique. Pictures of aortic longitudinal mid-plane perpendicular to leaflets pivots were acquired by a high speed camera (Mikrotron Eosens MC1362) with spatial resolution $1280 \times 1024$ pixels and at $500 \mathrm{fps}$ placed at an angle of $30^{\circ}$ with respect to the valvular ring plane. Angles $\alpha_{L}$ and $\alpha_{R}$ between the valve ring plane and leaflets were measured, assuming each occluder as a line going from the leaflet top to the hinge (Fig. 1c, left). Ten instants in the ejection period were chosen as relevant to sample the tilting angles (Fig. 1c, right).

\section{Velocity measurements}

The local flow field downstream the aortic valve between the valve ring and up about $2 \mathrm{~cm}$ over the sinotubular junction was measured using image analysis. To this aim, the working fluid was seeded with passive buoyant hollow glass particles (VESTOSINT $2157, \mathrm{D}_{\text {mean }}=30 \mu \mathrm{m}$, density $1.016 \mathrm{~g} / \mathrm{cm}^{3}$ ). The symmetrical vertical mid-plane of AA was lit by a $12 \mathrm{~W}$ infrared laser and flow images were acquired using a Mikrotron high speed camera at $500 \mathrm{fps}$ (time resolution $\Delta \mathrm{t}=2 \mathrm{~ms}$ ). Velocity fields were obtained using the Feature Tracking (FT) technique [41], in this case we considered $50 \times 51$ grid points, corresponding to a spatial resolution $\Delta \mathrm{s}=0.78 \mathrm{~mm}$. All the derived quantities needed to investigate the flow features (velocity gradients, mean flow and velocity fluctuations) were then evaluated. In particular, the maximum viscous shear stress $\tau_{\text {tmax }}$ was here calculated as $[41,56]$ :

$$
\tau_{\max }=\frac{\left(\tau_{1-} \tau_{2}\right)}{2}=2 \mu\left(\mathrm{e}_{1}-\mathrm{e}_{2}\right)
$$

where $\tau_{i}$ and $e_{i}$ are the eigenvalues of the stress tensor and the strain velocity tensor, respectively and $\mu$ is test fluid dynamic viscosity. Spatio-temporal resolution $\left(\Delta \mathrm{s} / \mathrm{D}=3 \times 10^{-2} ; \Delta \mathrm{t} / \mathrm{T}=\mathrm{O}\left(10^{-3}\right)\right)$ was estimated high enough to identify vortex structures in the investigated region, and to follow their evolution during the cardiac cycle. Experiments were performed in four combinations of the haemodynamic input conditions, namely SV $=64$ and $80 \mathrm{ml}$, and $\mathrm{T}=2.4$ and $2.6 \mathrm{~s}$. For each parameter combination, 100 consecutive cardiac cycles were acquired to compute phase averaged quantities. An Additional file 2: movie file shows the trajectories reconstruction procedure in one of 
the performed experiments [see Tracking.avi] and the phase averaged velocity fields are also included as Additional file 3 (see "Availability of data and materials" section).

\section{Results}

Global flow characteristics and prosthetic valve haemodynamic performance

Physiological [57] and in vitro waveforms of ventricular and aortic pressures are compared in Fig. 2. The obtained experimental waves mimic the main physiological characteristics, including the presence of the dicrotic notch at valve closure. The presence of pressures crossing, in the forward flow phase, confirms the in vitro phenomena for the BMHVs known as leaflet fluttering, also noticed by [30]. Moreover, in vitro minimum, maximum and mean values of both $\mathrm{p}_{\mathrm{a}}$ and $\mathrm{p}_{\mathrm{v}}$ are in the typical physiological range (Fig. 2). These results, together with the experimental aortic forward flow wave shown in Fig. 1c, assure that our laboratory facility satisfactorily reproduces the physiological flow conditions. Also we considered the measurement of the mean transvalvular pressure drop, $\Delta \mathrm{p}_{\mathrm{m}}$, and the EOA as they represent the global flow parameters in the ejection phase. We tested the haemodynamic performance of the valve under the physiological pulsatile flow conditions listed in Table 1. As expected, results show that different working conditions induce different $\Delta \mathrm{p}_{\mathrm{m}}$ and EOA values. In agreement with literature [11, $58,59]$ we found that the EOA is a growing function of SV while it decreases with $\mathrm{T}$ (Fig. 3).

\section{Leaflets dynamics}

Figure 4 shows the behavior of the measured right and left leaflets tilting angles $\left(\alpha_{R}\right.$ and $\alpha_{\mathrm{L}}$, respectively) versus the non-dimensional time $\mathrm{t} / \mathrm{T}$ for the three hydrodynamic conditions $\mathrm{T}=2.4 \mathrm{~s}, \mathrm{SV}=54,64$ and $80 \mathrm{ml}$. The performed measurements allow to describe the movement of the two single leaflets and to highlight the possible dependence of opening and closing valve dynamics on the local and global flow characteristics. Panels a-c illustrate the asynchronous dynamics of the two leaflets, in particular during

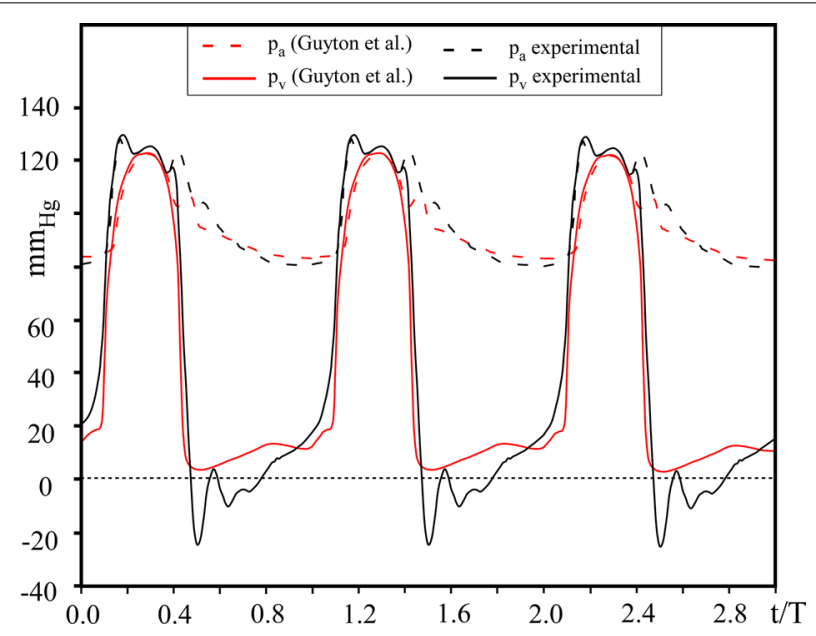

Fig. 2 Comparison between the ventricular $\left(p_{v}\right)$ and the aortic $\left(p_{a}\right)$ pressure behavior from medical literature (red lines, [53]) and in vitro test with the mock loop (black lines) 


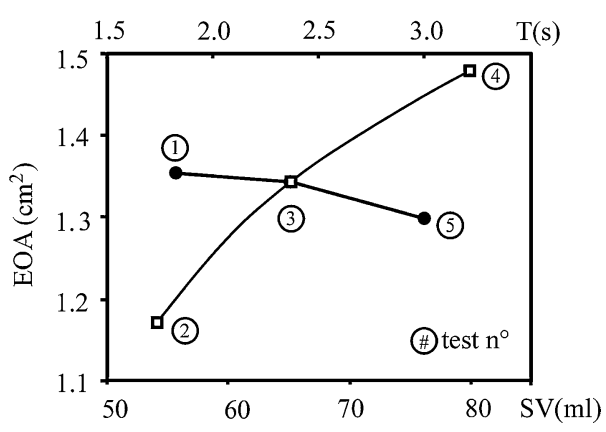

Fig. 3 EOA as a function of the SV (white squares) for the fixed physiological $T=2.4 \mathrm{~s}$, and as a function of the period (black dots), for SV $=64 \mathrm{ml}$ (experiments numbered as reported in Table 1)

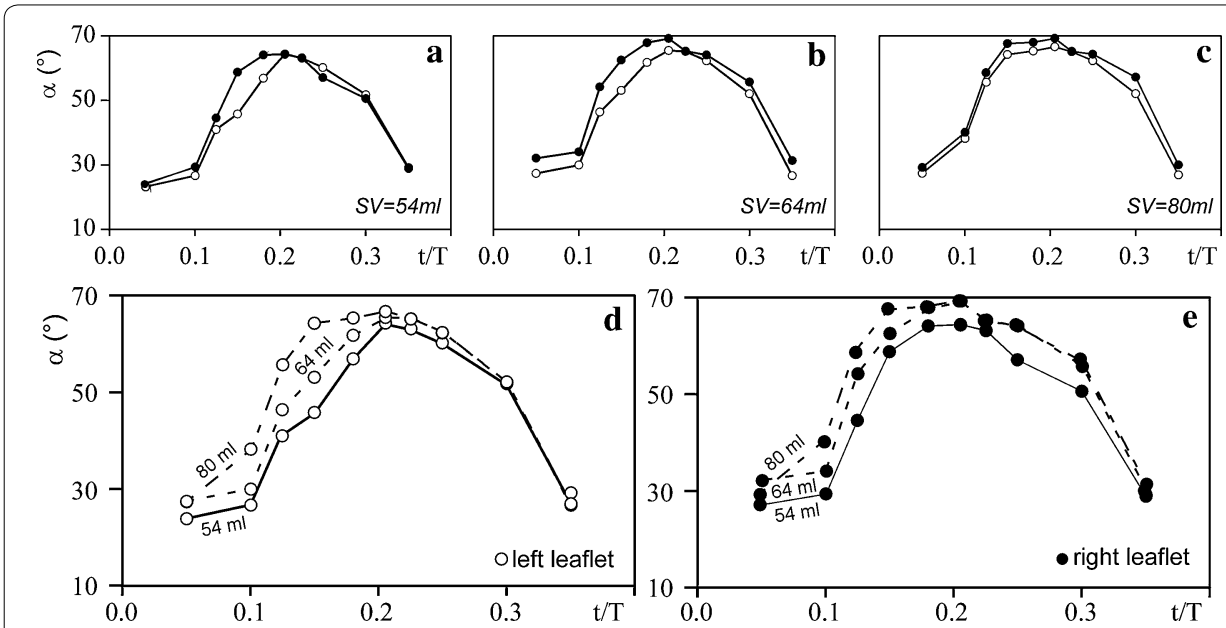

Fig. 4 Left $\left(a_{L}\right.$, white dot) and right $\left(a_{R}\right.$, black dot) leaflet tilting angles behavior in non-dimensional time $t / T$. a-c show the case $S V=54,64$ and $80 \mathrm{ml}$, respectively. $\mathbf{d}$, e show the trend between the same leaflet but at different SV.T $=2.4 \mathrm{~s}$ was used for all results

the opening phase, and show that the right leaflet usually opens at larger angle. Differences are reduced as the SV increases. Panels $d$ and e further clarify the effect of the SV on the leaflets dynamics: during the opening phase the tilting angle increases as the SV increases, on the contrary during the closing phase the variation of the SV has a less impact on it. A possible explanation for the observed asymmetry in leaflets movement might be in even minor differences in leaflets design/construction parameters as suggested by [10], who first observed the asymmetric kinematics of BHMVs leaflets. In the present case, asymmetry might be also related to the different orientation of the two leaflets with respect to the sinuses of Valsalva, as shown by numerical predictions reported in [60]. As recently demonstrated by [61], in fact, prosthetic valve-aortic root mutual configuration strongly affects flow characteristics in proximity of the valve. Hence, it can be here speculated that the geometric mismatch between the BHMV (which has a $120^{\circ}$ symmetry) and the root (with its $180^{\circ}$ symmetry) implies asymmetric flow field characteristics, which in turn drive the asymmetric behavior of the two leaflets [10]. 


\section{Local transvalvular flow}

Figure 5 illustrates the phase averaged velocity field and the distribution of non-dimensional vorticity for six representative time instants (red dot on the reported aortic flow rate curve) during the ejection phase, for experiment 3. Shortly after the valve opening $(\mathrm{t} / \mathrm{T}=0.140)$ the triple jet pattern developing from the valve is clearly visible [9]. However, the two lateral jets ( $\mathrm{A}$ and $\mathrm{B}$ for the left and right jet, respectively) are more intense than the central jet $C$, suggesting that the flow through lateral orifices starts to develop earlier than in the central region. Moreover, the jet emerging from the right leaflet (B) develops slightly earlier than the left one (A), according to the asymmetric phenomenon observed in the valve leaflets dynamics [62]. Such asymmetry should be related to the presence of the sinuses of Valsalva, as confirmed by the flow evolution at successive time instants [29]. At the peak of forward flow acceleration $(\mathrm{t} / \mathrm{T}=0.168)$ side jets $A$ and $B$ move upward to the aortic wall, farther B stretches up to the sinotubular junction more than jet A. A strong recirculating vortex generated by the left jet fills the sinuses of Valsalva, while only a smaller recirculation zone appears on the right side. The central jet is now of the same intensity of the side ones, but shortest. At $\mathrm{t} / \mathrm{T}=0.195$ (peak systole) two structures $\left(\mathrm{A}^{\prime}\right.$ and $\mathrm{B}^{\prime}$ in the vorticity map) separate from the two side jets and form a vortex ring that moves up leaving the investigated region $(\mathrm{t} / \mathrm{T}=0.222)$. At that instant, the vorticity layers in correspondence of the boundaries continue to move upwards, decreasing in intensity. During the deceleration phase $(\mathrm{t} / \mathrm{T}=0.290)$ a significant decreasing of the vorticity intensity is observed, in particular

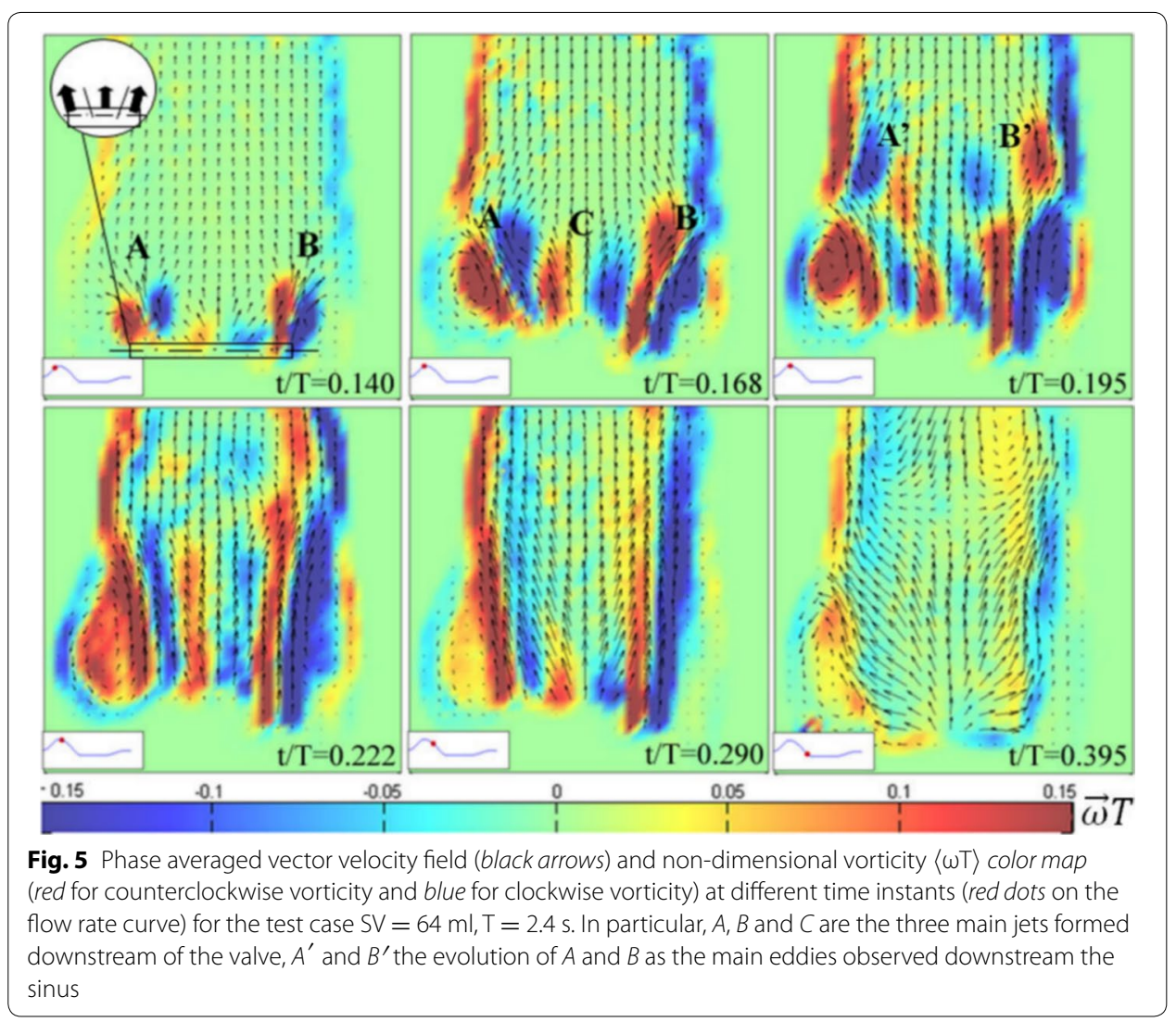


this is evident in correspondence of the sinuses of Valsalva. At the end of the systolic ejection $(t / T=0.395)$ the valve closure is marked by a flow inversion appearing in the upper part of the aortic root. Noteworthy, a flow asymmetry can still be appreciated, thus suggesting a possible asymmetry in the leaflets closing dynamics.

Figure 6 shows the phase-averaged velocity field and the spatial distribution of the non-dimensional maximum viscous shear stress $\tau_{\text {tmax }} / \rho U^{2}$ at four time instants in the ejection phase, for the same experiment. The valve induces a complex texture of high shear layers, due to the development of the three jets. Both the distribution and the magnitude of $\tau_{\text {tmax }} / \rho U^{2}$ present a strong asymmetry with respect to the longitudinal axis, the region close to the right leaflet is indeed the mostly solicited. Again this asymmetry resembles the one observed in the valve dynamics. Results also show how regions characterized by higher values of maximum shear stress (i.e. $\tau_{t \max } / \rho \mathrm{U}^{2} \geq 0.2-0.25$ ) are not confined in the region close to the valve. As time evolves, they rather tend to extend along the root boundary up to distances equal to more than twice the vessel diameter. Moreover, the residence time of $\tau_{\operatorname{tmax}} / \rho \mathrm{U}^{2} \geq 0.2-0.25$ is larger than two-thirds of the ejection period. Spatial distribution and temporal duration of maximum shear stress then give a preliminary, but fundamental, information about the potential damage on blood cells due to the action of the flowing fluid across the valve.

\section{Potential damage to blood particles}

In biomedical devices, such as MHVs, shear stress distribution is usually quite far from the physiological condition both for spatial distribution and amplitude, thus demanding the quantification of shear-induced blood trauma to assess the safety and efficacy of the device prior to its marketing $[1,53]$.

Shear stress level and duration are recognized as primary factors driving blood trauma [54]. Hence we averaged the maximum shear stress over the investigated area to compare its overall behaviour during the whole cycle for different haemodynamic working conditions. To this aim we plotted the non-dimensional averaged stress $\overline{\tau_{\text {tmax }}} / \rho \mathrm{U}^{2}$ as a function of $\mathrm{t} / \mathrm{T}$ (Fig. 7). Results show that maximum of $\overline{\tau_{\operatorname{tmax}}} / \rho \mathrm{U}^{2}$ increase with both SV and $\mathrm{T}$, the effect of $\mathrm{T}$ becoming smaller for larger SVs. Moreover, the area underlying the curves seems to depend on both SV and T, suggesting that blood cells damage due to mechanical stresses in time is possibly sensitive to bulk flow conditions. The above idea was explored by calculating a first estimation of red cells HI. In the power law here

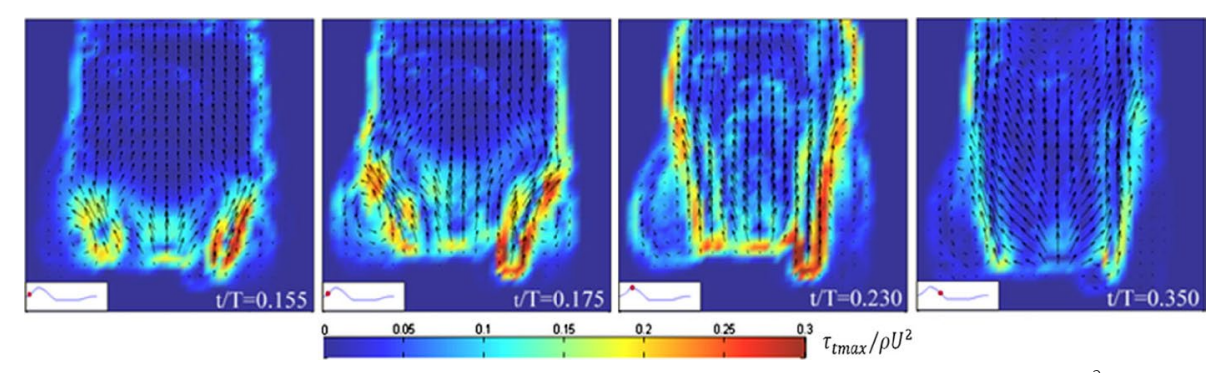

Fig. 6 Phase averaged velocity field and non-dimensional maximum viscous shear stress $\tau_{\mathrm{tmax}} / \mathrm{\rho U}^{2}$ (color map) at different time instants for the test case $S V=64 \mathrm{ml}, T=2.4 \mathrm{~s}$ 


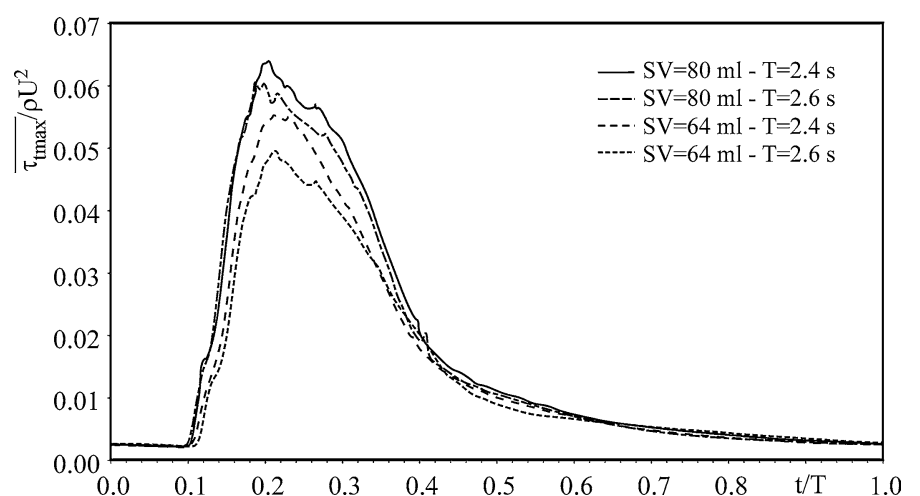

Fig. 7 Non-dimensional maximum shear stress averaged over the aortic root area $\bar{\tau}_{\text {tmax }} / \rho U^{2}$ as a function of non-dimensional time $\mathrm{t} / \mathrm{T}$ for different haemodynamic working conditions

considered to evaluate $\mathrm{HI}$, the exposure time $t_{\text {exp }}$ was calculated as the time required to cross the investigated region with average velocity $U$ while the 'active' shear stress $\tau$ was assumed equal to the maximum value of $\bar{\tau}_{\text {tmax }}$. The following values were recovered: $\mathrm{HI}=0.0000284 \%$ for $\mathrm{SV}=64 \mathrm{ml}, \mathrm{T}=2.4 \mathrm{~s} ; \mathrm{HI}=0.0000701 \%$ for $\mathrm{SV}=80 \mathrm{ml}, \mathrm{T}=2.4 \mathrm{~s}$; $\mathrm{HI}=0.0000205 \%$ for $\mathrm{SV}=64 \mathrm{ml}, \mathrm{T}=2.6 \mathrm{~s} ; \mathrm{HI}=0.0000507 \%$ for $\mathrm{SV}=80 \mathrm{ml}, \mathrm{T}=2.6 \mathrm{~s}$. Thus, HI was found to increase quite significantly with SV (with an estimated factor of about 2.5 from $\mathrm{SV}=64 \mathrm{ml}$ to $\mathrm{SV}=80 \mathrm{ml}$ ) and to slightly decrease as $\mathrm{T}$ increases (with an estimated factor of about 0.7 from $\mathrm{T}=2.4 \mathrm{~s}$ to $\mathrm{T}=2.6 \mathrm{~s}$ ). Interestingly, the computed values of $\mathrm{HI}$ are not far from previous studies and about one order of magnitude smaller than those estimated after one passage through the healthy blood system $(\mathrm{HI}=0.00058 \%$, value reported in [38]), suggesting the safety of the tested valve from the haemolysis point of view although a reliable estimation of blood trauma potential of mechanical valves is far from being a sufficiently clarified issue due to the limitations of a power-law approach and the scarcity of experimental data on RBCs in physiological flows. A specific study on this topic, based on the present results, is currently in progress.

\section{Conclusions}

Global haemodynamic performance of a BMHV in aortic position was tested measuring simultaneously different metrics varying the hydrodynamic working conditions, allowing an all-around view of the valve behaviour. In particular, we considered transvalvular pressure drop and EOA, leaflets opening/closing angle, local velocity and shear stresses, potential damage of blood cells. Results allowed to appreciate the asynchronous behaviour of the two leaflets, possibly due to their different orientation with respect to the sinuses of Valsalva and to even minor differences in leaflets design. The local flow field analysis showed the presence of asymmetric fluid structures particularly evident in the shear stress distribution. The shear stress in the region close to the valve allowed a first estimate of the potential damage of red blood cells due to mechanical action; also variations in the HI were found as the bulk flow conditions were varied. 
The benefit of an integrated approach stimulates some observations that can be made only analysing the results from a comprehensive perspective:

- both the EOA and the HI were found to be affected by bulk flow conditions; in particular, they both increase with SV and as T decreases, thus suggesting that the global and the local performance of the prosthesis show opposite trend with changes in the haemodynamic regime. In other words, the optimization of the overall prosthetic valve performan*ce results from the best possible compromise in the control of heart work overload and blood cells damage due to the valve itself. Moreover, also the leaflets dynamics was found to improve (in both leaflets synchronicity and maximum opening angle) with a SV increasing. We can hence speculate that flow dependence of the EOA (i.e. of the global performance of the prosthesis) actually is a consequence of the response of valve dynamics to flow changes. On the contrary the local performance, or at least the haemolytic potential, seems to appear more sensitive to flow intensity variations per se than to geometrical orifice area, although improved as a consequence of larger flow.

- A strong asymmetry in the shear stress distribution was observed. A relevant clinical implication can be seen in that result, which can possibly explain the asymmetric distribution of pannus/thrombotic deposits that is sometimes reported for explanted BMHV $[38,63]$. Whether local flow dynamics asymmetry is related to the asynchronous behaviour of valve leaflets and/or vice versa, and the latter to valve implant orientation with respect to the sinuses of Valsalva, deserves further investigation. A promising approach might be seen in a combination of in vitro tests like those here presented and in silico tests able to predict blood particles trauma [10, 40].

\section{Availability of data and materials}

The dataset supporting this study-in which results and discussion sections are basedare included within the article as additional files: one spreadsheet for the pressure fields across the valve (pressure_data.xls) and 8 for the velocity fields ( 2 for each of the 4 experiments performed, corresponding to the horizontal and vertical components) within the investigated domain.

As far as the pressures are concerned, the reported tests are labelled following Table 1. Each test columns report: the experiment time, the ventricular pressure, the aortic pressure, and the displacement acquired by the LVDT sensor placed at the bellow. Each acquisition is composed by 1200 samples.

As far as the velocity fields are concerned, the phase averaged velocity fields corresponding to the experiments:

- $\mathrm{SV}=64 \mathrm{ml} ; \mathrm{T}=2.4 \mathrm{~s} \mathrm{~T}=2.6 \mathrm{~s}$ (U_64_2_4.dat, V_64_2_4.dat; U_64_2_6.dat, V_64_2_6.dat)

- $\mathrm{SV}=80 \mathrm{ml} ; \mathrm{T}=2.4 \mathrm{~s} \mathrm{~T}=2.6 \mathrm{~s}$ (U_80_2_4.dat, V_80_2_4.dat; U_80_2_6.dat, V_80_2_6.dat) have included. Each file represent the time history of the corresponding velocity component: the number of rows corresponds to the size of the velocity field $(50 \times 51)$ while the number of columns corresponds to the number of acquired frames (1118 for experiments @ $\mathrm{T}=2.6 \mathrm{~s}, 1132$ for experiments @ $\mathrm{T}=2.4 \mathrm{~s}$ ). 


\section{Additional files}

Additional file 1. Pressure data

Additional file 2. Evolution of fluid particle trajectories.

Additional file 3. Velocity data for the performed experiments.

\section{Abbreviations}

MHV: mechanical heart valve; BMHV: bileaflet mechanical heart valve; EOA: effective orifice area; RBC: red blood cells; PD: pulse duplicator; AA: ascending aorta; LVOT: left ventricle outflow tract; SV: stroke volume; FT: feature tracking; HI: haemolysis index.

\section{Authors' contributions}

FS and GQ conceived the study; all authors participated in its design and coordination and helped to draft the manuscript; SE, RT and SF performed the pressure and flow measurements and the data analysis. All authors read and approved the final manuscript.

\section{Author details}

${ }^{1}$ Department of Civil and Environmental Engineering, Sapienza University of Rome, Rome, Italy. ${ }^{2}$ Cardiovascular Fluid Dynamics Laboratory HER, Department of Civil, Environmental and Architectural Engineering, University of Padua, Padua, Italy. ${ }^{3}$ Department of Civil, Environmental Engineering and Architecture, University of Cagliari, Cagliari, Italy.

\section{Acknowledgements}

Not applicable.

\section{Competing interests}

The authors declare that they have no competing interests.

\section{Funding}

This work was partially supported by MIUR Grant No. PRIN-2012HMR7CF.

Received: 23 July 2016 Accepted: 17 January 2017

Published online: 16 February 2017

\section{References}

1. Dasi LP, Simon HA, Sucosky P, Yoganathan AP. Fluid mechanics of artificial heart valves. Clin Exp Pharmacol. 2009;36(2):225-37.

2. Roger VL, Go AS, Lloyd-Jones DM, Adams RJ, Berry JD, Brown TM, Carnethon MR, Dai S, De Simone G, Ford ES, Fox CS, Fullerton HJ, Gillespie C, Greenlund KJ, Hailpern SM, Heit JA, Ho PM, Howard VJ, Kissela BM, Kittner SJ, Lackland DT, Lichtman JH, Lisabeth LD, Makuc DM, Marcus GM, Marelli A, Matchar DB, McDermott MM, Meigs JB, Moy CS, Mozaffarian D, Mussolino ME, Nichol G, Paynter NP, Rosamond WD, Sorlie PD, Stafford RS, Turan TN, Turner MB, Wong ND, Wylie-Rosett J. Heart disease and stroke statistics - 2011 update: a report from the American Heart Association. Circulation. 2011;123(4):18-209.

3. Faludi R, Szulik M, D'hooge J, Herijgers P, Rademakers F, Pedrizzetti G, Voigt JU. Left ventricular flow patterns in healthy subjects and patients with prosthetic mitral valves: an in vivo study using echocardiographic particle image velocimetry. J Thorac Cardiovasc Surg. 2010;139:1501-10

4. von Knobelsdorff-Brenkenhoffa F, Trauzeddela R, Barkerb A, Gruettnera H, Marklb M, Schulz-Mengera J. Blood flow characteristics in the ascending aorta after aortic valve replacement-a pilot study using 4D-flow MRI. Int J Cardiol. 2010;170:426-33.

5. Ismeno G, Renzulli A, Carozza A, De Feo M, lannuzzi M, Sante P, Cotrufo M. Intravascular haemolysis after mitral and aortic valve replacement with different types of mechanical prostheses. Int J Cardiol. 1999;69:179-83.

6. Ge L, Sotiropoulos F. Direction and magnitude of blood flow shear stresses on the leaflets of aortic valves: is there a link with valve calcification? J Biomech Eng. 2010;132(1):014505.

7. Sabbah HN, Hamid MS, Stein PD. Estimation of mechanical stresses on closed cups of porcine bioprosthetic valves: effects of stiffening, focal calcium and focal thinning. Am J Cardiol. 1985;65(8):1091-6.

8. Raghav VR, Okafor I, Quach M, Dang L, Marquez S, Yoganathan AP. Long-term durability of Carpentier-Edwards Magna Ease valve: a one billion cycle in vitro study. Ann Thorac Surg. 2016;101(5):1759-65.

9. Yoganathan AP, Chandran KB, Sotiropulos F. Flow in prosthetic heart valves: state-of-the-art and future directions. Ann Biomed Eng. 2005;33(12):1689-94.

10. Dasi LP, Ge L, Simon HA, Sotiropoulos F, Yoganathan AP. Vorticity dynamics of a bileaflet mechanical heart valve in an axisymmetric aorta. Phys Fluids. 2007;19(067105-1):17.

11. Gerosa G, Tarzia V, Rizzoli G, Bottio T. Small aortic annulus: the haemodynamic performances of 5 commercially available tissue valves. J Thorac Cardiovasc Surg. 2006:131(5):1058-64.

12. Grigioni M, Daniele C, D’Avenio G, Morbiducci U, Del Gaudio C, Abbate M, Di Meo D. Innovative technologies for the assessment of cardiovascular medical devices: state-of-the-art techniques for artificial heart valve testing. Expert Rev Med Devices. 2004;1(1):81-93.

13. Guivier C, Deplano V, Pibarot P. New insights into the assessment of the prosthetic valve performance in the presence of subaortic stenosis through a fluid-structure interaction model. J Biomech. 2007;40(10):2283-90. 
14. Leo HL, Prasad D, Carberry J, Simon AH, Yoganathan AJ. Fluid dynamic assessment of three polymeric heart valves using particle image velocimetry. Ann Biomed Eng. 2006;34(6):936-52.

15. Lim WL, Chew YT, Chew TC, Low HT. Steady flow dynamics of prosthetic aortic heart valves: a comparative evaluation with PIV techniques. J Biomech. 1998;31(5):411-21.

16. Sodian R, Hoerstrup SP, Sperling JS, Daebritz S, Martin DP, Moran AM, Kim BS, Schoen FJ, Vacanti JP, Mayer JE Jr. Early in vivo experience with tissue-engineered trileaflet heart valves. Circulation. 2000;102(19 Suppl 3):III22-9.

17. Blais C, Burwash IG, Mundigler G, Dumesnil JG, Loho N, Rader F, Baumgartner H, Beanlands RS, Chayer B, Kadem L, Garcia D, Durand LG, Pibarot P. Projected valve area at normal flow rate improves the assessment of stenosis severity in patients with low-flow, low-gradient aortic stenosis the multicenter TOPAS (Truly or Pseudo-Severe Aortic Stenosis) study. Circulation. 2006;113:711-21.

18. Clavel MA, Burwash IC, Mundigler G, Dumesnil JG, Baumgartner H, Bergler-Klein J, Sénéchal M, Mathieu P, Couture C Beanlands R, Pibarot P. Validation of conventional and simplified methods to calculate projected valve area at normal flow rate in patients with low flow, low gradient aortic stenosis: the multicenter TOPAS (True or Pseudo Severe Aortic Stenosis) study. J Am Soc Echocardiogr. 2010;23(4):380-6.

19. Poh KK, Levine RA, Solis J, Shen L, Flaherty M, Kang YJ, Guerrero JL, Hung J. Assessing aortic valve area in aortic stenosis by continuity equation: a novel approach using real-time three-dimensional echocardiography. Eur Heart J. 2008:29:2526-35.

20. Scotten LN, Walker DK. New laboratory technique measures projected dynamic area of prosthetic heart valves. J Heart Valve Dis. 2004;13(1):120-33.

21. Shipkowitz T, Ambrus J, Kurk J, Wickramasinghe K. Evaluation technique for bileaflet mechanical valves. J Heart Valve Dis. 2002;11(2):275-82.

22. Arjunon S, Ardana PH, Saikrishnan N, Madhani S, Foster B, Glezer A, Yoganathan AP. Design of a pulsatile flow facility to evaluate thrombogenic potential of implantable cardiac devices. J Biomech Eng. 2015;137:045001-9.

23. Nobili M, Morbiducci U, Ponzini R, Del Gaudio R, Balducci A, Grigioni M, Montevecchi FM, Redaelli A. Numerical simulation of the dynamics of a bileaflet prosthetic heart valve using a fluid-structure interaction approach. J Biomech. 2008:41:2539-50.

24. Astorino M, Gerbeau JF, Pantz O, Traoré KF. Fluid-structure interaction and multi-body contact: application to aortic valves. Comput Methods Appl Mech Eng. 2009;198:3603-12.

25. De Hart J, Peters GWM, Schreurs PJG, Baaijens FPT. A three-dimensional computational analysis of fluid-structure interaction in the aortic valve. J Biomech. 2013;36(1):103-12.

26. De Tullio MD, Nam J, Pascazio G, Balaras E, Verzicco R. Computational prediction of mechanical haemolysis in aortic valved prostheses. Eur J Mech B Fluids. 2012;35:47-53.

27. Van Loon R. Towards computational modelling of aortic stenosis. Int J Numer Methods Biomed Eng. 2010:26:405-20

28. Krafczyk M, Cerrolaza M, Schulz M, Rank E. Analysis of 3D transient blood flow passing through an artificial aortic valve by Lattice-Boltzmann methods. J Biomech. 1998;31(5):453-62.

29. Smadi O, Hassan I, Pibarot P, Kadem L. Numerical and experimental investigations of pulsatile blood flow pattern through a dysfunctional mechanical heart valve. J Biomech. 2010;43:1565-72.

30. Grigioni M, Daniele C, Romanelli C, Barbaro V. Report ISTISAN 03/21, 2003. ISSN: 1123-3117.

31. Hasenkam JM, Westphal D, Wygaard H, Reul H, Giersiepen M, Stodkilde H. In vitro stress measurements in the vicinity of six mechanical aortic valves using hot-film anemometry in steady flow. J Biomech. 1988;21(3):235-47.

32. Simon HA, Dasi LP, Leo HL, Yoganathan AP. Spatio-temporal flow analysis in bileaflet heart valve hinge regions: potential analysis for blood element damage. Ann Biomed Eng. 2007;35(8):1333-46.

33. Yap $\mathrm{CH}$, Saikrishnan $\mathrm{N}$, Yoganathan AP. Experimental measurement of dynamic fluid shear stress on the ventricular surface of the aortic valve leaflet. Biomech Model Mechanobiol. 2012:11:231-44.

34. Yoganathan AP, Woo Y, Sung H. Turbulent shear stress measurements in the vicinity of aortic heart valve prostheses. J Biomech. 1986;19(6):433-42.

35. Alemu Y, Bluestein D. Flow-induced platelet activation and damage accumulation in a mechanical heart valve: numerical studies. Artif Organs. 2007;31:677-88.

36. Dumont K, Vierendeels J, Kaminsky R, Van Nooten G. Comparison of the haemodynamic and thrombogenic performance of two bileaflet mechanical heart valves using a CFD/FSI model. J Biomech Eng. 2007;129:558-65.

37. Fraser KH, Zhang T, Taskin ME, Griffith BP, Wu ZJ. A quantitative comparison of mechanical blood damage parameters in rotary ventricular assist devices: shear stress, exposure time and haemolysis index. J Biomech Eng. 2012;129(081002):1-11.

38. Goubergrits L. Numerical modeling of blood damage: current status, challenges and future prospects. Expert Rev Med Devices. 2006;3(5):527-31.

39. Morbiducci U, Ponzini R, Nobili M, Massai D, Montevecchi FM, Bluestein D, Redaelli A. Blood damage safety of prosthetic heart valves. Shear-induced platelet activation and local flow dynamics: a fluid-structure interaction approach. J Biomech. 2009;42:1952-60.

40. Toninato R, Fadda G, Fortini S, Espa S, Querzoli G, Susin FM. Coupling PIV Measurements and numerical modelling of RBCs mechanics to predict thrombogenicity of mechanical prosthetic heart valves, WCB 2014, Boston 1-7 July 2014 ISBN: 978-1-63439-381-2.

41. Cenedese A, Del Prete Z, Miozzi M, Querzoli G. A laboratory investigation of the flow in the left ventricle of a human heart with prosthetic, tilting disk valves. Exp Fluids. 2005;39(2):322-35.

42. Espa S, Badas MG, Fortini S, Querzoli G, Cenedese A. A Lagrangian investigation of the flow inside the left ventricle. Eur J Mech B Fluids. 2012;35(1):9-19.

43. Fortini S, Querzoli G, Espa S, Cenedese A. Three-dimensional structure of the flow inside the left ventricle of the human heart. Exp Fluids. 2013;54:1609-19.

44. Querzoli G, Fortini S, Cenedese A. Effect of the prosthetic mitral valve on vortex dynamics and turbulence on the left ventricular flow. Phys Fluids. 2010;22(4):041901-10.

45. Vukicevic M, Fortini S, Querzoli G, Espa S, Pedrizzetti G. Experimental study of the asymmetric heart valve prototype. Eur J Mech B Fluids. 2012;35:54-60. 
46. Querzoli G, Fortini S, Espa S, Costantini M, Sorgini F. Fluid dynamics of aortic root dilation in Marfan syndrome. J Biomech. 2014;47:3120-8

47. Fortini S, Espa S, Querzoli G, Cenedese A. Turbulence investigation in a laboratory model of the ascending aorta. J Turbul. 2015;16(3):208-24.

48. Isnard RN, Pannier BM, Laurent S, London GM, Diebold B, Safar ME. Pulsatile diameter and elastic modulus of the aortic arch in essential hypertension: a noninvasive study. J Am Coll Cardiol. 1989;13(2):399-405.

49. Baumgartner D, Baumgartner C, Mátyás G, Steinmann B, Löffler-Ragg J, Schermer E, Schweigmann U, Baldissera I, Frischhut B, Hess J, Hammerer I. Diagnostic power of aortic elastic properties in young patients with Marfan syndrome. J Thorac Cardiovasc Surg. 2005;129:730-9.

50. Josa M, Castellá M, Paré C, Bedini JL, Cartañá R, Mestres CA, Pomar JL, Mulet J. Haemolysis in mechanical bileaflet prostheses: experience with the Bicarbon valve. Ann Thorac Surg. 2006:81 (4):1291-6.

51. Misawa Y, Saito T, Konishi H, Oki S, Kaminishi Y, Sakano Y, Morita H, Aizawa K. Clinical experience with the Bicarbon heart valve prostheses. J Cardiothoracic Surg. 2007;25:2-8.

52. ISO 5840-2:2015 Cardiovascular implants_Cardiac valve prostheses_-Part 2: Surgically implanted heart valve substitutes. http://www.iso.org/iso/catalogue_detail.htm?csnumber=51314.

53. Taskin ME, Fraser KH, Zhang T, Wu C, Griffith BP, Wu ZJ. Evaluation of Eulerian and Lagrangian models for haemolysis estimation. ASAIO J. 2012;58:363-72.

54. Grigioni M, Morbiducci U, D'Avenio G, Di Benedetto G, Del Gaudio C. A novel formulation for blood trauma prediction by a modified power-law mathematical model. Biomech Model Mechanobiol. 2005;4:249-60.

55. Giersiepen M, Wurzinger $\sqcup$, Opitz R, Reul H. Estimation of shear stress-related blood damage in heart valve prostheses-in vitro comparison of 25 aortic valves. Int J Artif Organs. 1990;13(5):300-6.

56. Grigioni M, Daniele C, D'Avenio G, Barbaro V. Evaluation of the surface-averaged load exerted on a blood element by the Reynolds shear stress field provided by artificial cardiovascular devices. J Biomech. 2002;35:1613-22.

57. Guyton AC, Hall JE. Textbook of medical physiology. 11th ed. Philadelphia: Elsevier Saunders; 2006.

58. Garcia D, Pibarot P, Durand P. Analytical modeling of the instantaneous pressure gradient across the aortic valve. J Biomech. 2005;38(6):1303-11.

59. Walker DK, Brendzel AW, Scotten LN. The new St. Jude Medical regent mechanical heart valve: laboratory measurements of haemodynamic performance. J Heart Valve Dis. 1999;8(6):687-96.

60. Borazjani I, Sotiropoulos F. The effect of implantation orientation of a bileaflet mechanical heart valve on kinematics and haemodynamics in an anatomic aorta. J Biomech Eng. 2010;132(11):111005.

61. Toninato R, Salmon J, Susin FM, Ducci A, Burriesci G. Physiological vortices in the sinuses of Valsalva: an in vitro approach for bio-prosthetic valves. J Biomech. 2016;49:2635-43.

62. Akutsu T, Matsumoto A. Influence of three mechanical bileaflet prosthetic valve designs on the three-dimensional flow field inside a simulated aorta. J Artif Organs. 2010;13:207-17.

63. Chan J, Marwan M, Schepis T, Ropers D, Du L, Achenbach S. Cardiac CT Assessment of prosthetic aortic valve dysfunction secondary to acute thrombosis and response to thrombolysis. Circulation. 2009;120:1933-4.

Submit your next manuscript to BioMed Central and we will help you at every step:

- We accept pre-submission inquiries

- Our selector tool helps you to find the most relevant journal

- We provide round the clock customer support

- Convenient online submission

- Thorough peer review

- Inclusion in PubMed and all major indexing services

- Maximum visibility for your research

Submit your manuscript at www.biomedcentral.com/submit 